Andrzej Szymanek

\title{
SYSTEM APPROACH IN ROAD SAFETY STUDIES
}

The road safety management methodology should be based on a system approach. This means that the road transport must be formalized as a complex system (CS), and then safety can be interpreted as an emergent feature of such a system. Road accidents should be interpreted as "organizational accidents". They should be studied using concepts such as "normal accident theory" (NAT) and "highly reliable organization" (HRO). The main purpose of the article is to show the usefulness of these concepts for the road safety and risk management, especially in Polish conditions. The system approach to road safety research (and transport safety) will allow for the better safety results.

Keywords: road safety, road risk management, system approach, complex systems

\section{Introduction}

Road transport generates the highest social costs, including the costs of: road accidents, environmental degradation, congestion. Among them, the costs of road accidents are the highest. Therefore, one of the four main objectives of the road transport management is to minimize the number of road accidents, as well as reduction of fatal and serious accidents.

Paradoxically, a coherent safety management methodology does not yet exist. Road transport must be described as a complex system and it follows that there is the need for a systemic approach to road safety management.

Effective transport safety management is management according to the objectives set out for the transport system under consideration.

The road safety management is a system management, whereby an acceptable risk of traffic accidents and/or risks of other road incidents over a specific period and in a specific area is managed.

\section{Road transport is a system with the greatest potential for the risk reduction}

This system, which generates higher costs, also has greater potential to reduce them. The road transport generates the highest costs and therefore through effective risk management a relatively greater reduction of losses could be achieved, thus reducing costs.

The primacy of the road transport in generating external costs is confirmed by various indicators. These relate primarily to the risk of fatal and serious accidents, as well as the costs of environmental degradation. Below there are two indicators that show that the road transport is the most dangerous and socially expensive, Table 1 [1], Table 2 [2].
Here are some of the more important characteristics of road accidents [3]:

1. The road safety is a major public health concern; in 2016, around 1.35 million people died in road accidents worldwide;

2. Today, it is estimated that macroeconomic losses due to road accidents will cost the world economy almost USD 1.8 trillion between 2015 and 2030. This number is higher than the total GDP of Canada in 2017 (the tenth largest world economy) [4];

3. Macroeconomic costs of road accidents vary in different regions of the world. The highest aggregate economic burden is in the USA (USD 487 billion) and in China (USD 364 billion). For Poland, this burden is estimated at USD 15.7 billion. On the other hand, average costs of road accidents, calculated (in USD) per capita, are the highest in Luxembourg (1465). For Poland this indicator has a value of 417 USD. It is estimated that the average annual economic burden of the road accidents will amount to $0.12 \%$ of the world GDP in the coming decade, with the average burden per capita amounting to 231 USD [4].

The 2018 WHO report describes the level of the road safety and the costs of road transport [3]:

1. Road accidents are the 8th cause of death worldwide for all the age groups and the main cause of death for children and young people aged 5-29 years;

2. More than half of all the road fatalities involve unprotected road users;

3. Road accident mortality rates are more than three times higher in the low-income countries than in the high-income countries.

In 2018, 25100 fatalities were recorded on the roads of the European Union, meaning a decrease of $21 \%$ compared to 2010 . The average road mortality rate in 2018 in the EU was 49 deaths per 1 million inhabitants. Nevertheless, it is doubtful that the planned $50 \%$ reduction in the number

Andrzej Szymanek

Faculty of Transport and Electrical Engineering, Kazimierz Pulaski University of Technology and Humanities in Radom, Poland E-mail of corresponding author: a.szymanek@uthrad.pl 
Table 1 Annual Average Probability of Fatal Transport Accident (AAPFTA) [1]

\begin{tabular}{cccc}
\hline Transport type & AAPFTA & Transport type & AAPFTA \\
\hline Road transport & $2.25 \bullet 10^{-4}$ & Rail transport & $75 \bullet 10^{-7}[30$ times smaller $]$ \\
Sea transport & $5 \bullet 10^{-5}[4.5$ times smaller $]$ & Air transport & $17 \bullet 10^{-7}[132$ times smaller $]$ \\
\hline
\end{tabular}

Table 2 Average costs of transport accidents, (2000) [2]

\begin{tabular}{lcccccc}
\hline \multicolumn{5}{c}{ Transport } \\
\hline Road & Rail & Air & Road & Rail & Air & Water \\
\hline \multicolumn{2}{l}{ Passenger transport $\left[\right.$ euro $/ 10^{3}$ vehicle-km] } & & Freight transport $\left[\right.$ euro $/ 10^{3}$ tons-km] \\
32.4 & 0.8 & 0.4 & 7.6 & 0.0 & 0.0 & 0.0 \\
\hline
\end{tabular}

of fatal accidents will be achieved in the ending decade 2010-2020.

In the Europe on the Move package from May 2018, the European Commission proposed a new approach to road safety policy for 2021-2030. The long-term goal is to bring the number of fatalities and serious injuries in road transport closer to zero by 2050 . The closest new intermediate target is to reduce the number of road fatalities by $50 \%$ by 2030 [5-6].

\section{$3 \quad$ Road safety as a research problem}

One of the many effects of traffic intensification was an increase of number of road accidents. The reaction to this phenomenon was planning various road safety strategies. The historical order and context of these strategies is discussed by Lu at works [7-8].

The reports of the Organization for Economic Co-operation and Development, (OECD) highlighted several major aspects of the road safety issues that have gained particular importance in theoretical work and road safety research at the beginning of the 21st century.

Among other things, a great need to build the road safety theories and models was pointed out [9]: "Unfortunately, the lack of theoretical basis is more common in road safety research than in many other research fields. (...) There is a lack of new research hypotheses and formulation of general principles of counteracting".

Safety defined in terms of accepted losses. As a scientific concept or construct - "road safety" is usually interpreted by political decision-makers, traffic experts, the media and the public opinion - as a category representing the total number of road accidents and their results (fatalities and injuries of different severity) in a given time period.

A different - according to the author, more creative is interpretation of "road safety" given by N.G. Levenson [10]: Freedom from accidents or losses. (...) safety should be defined in terms of acceptable losses". Levenson adds: Deciding on the level of acceptable losses is obviously not a trivial issue and contains complex and ethically contentious forms of socioeconomic evaluation at the political level. This was already a definition that announced the need to handle and manage risk. The key issue here is decision making - determining the level of acceptable losses. And that is the problem of the risk assessment.

\section{Three important elements for systemic road transport safety studies}

Safety studiesas a "tied discipline". One form of discipline integration is clustering, when a single idea becomes an axis of interest for several disciplines. This idea can be a phenomenon, a problem, a person, a geographical area, or other. Specialists from different disciplines study a common theme from the perspective of their own disciplines. This is how a "bonded discipline" arises. It seems that such a knotty idea may be the "transport safety". A thesis can be formulated, [11]: "transport safety" is a nodal idea that binds research on different branches of transport. It is an interdisciplinary research".

OECD experts for a long time have stressed the need for a multidisciplinary approach to road safety research [9].

Geysen's thesis as a tool for a broad view understanding of safety issues

W. Geysen in his work [12] formulated as obvious as inspiring thesis: “(...) safety problems in different areas are very often of the same nature and can be formalized in the same way". This thesis allows to search for principles and methods of effective road transport safety management in other systems.

Geysen's thesis allows the use of: reasonable analogies, recognized theoretical concepts and some safety models for safety transport studies. Among other things, the aim is to critically review the known safety principles and implement them in the field of transport. However, when seeking reasonable analogies, it is important to keep in mind the characteristics of transport and road transport particularly. Geysen's thesis provides a methodological basis for research of the road transport safety, based on the philosophical and methodological canons of Safety Science.

Safety in any system can be considered on four levels [12]:

1. level of the "safety philosophy" - setting safety criteria and expected losses; 
2. the level of investigation of ways and methods, which may be useful in improving safety;

3. the level of "safety technology" - implementation of safety improvement techniques;

4. level of "safety policy" - compilation of knowledge and practice of levels 1-2-3.

Haddon's idea. The system approach to road safety research was applied by Haddon, which in the model " 3 phases of accident - 3 groups of risk factors" showed the idea of systematic "safety intervention management" in the road traffic. He spoke about the need for "comprehensive systemic treatment". In his model he presented an epidemiological approach to road accidents as a "disease"; he distinguished three phases of the disease and a triad of general causative factors: man, vehicle, environment. Treatment of such a disease would consist of interventions in each of these phases and in each group of risk factors, thus in each of the nine "Haddon's cells" [13]

Haddon's model can be interpreted - this is the author's view - as a variant of the principle of defense in depth; it also resembles the "blunt-sharp-end" model. And no wonder - both of these tools, although formally different from the point of view of safety philosophy, are similar and describe well the essence of systemic approach to safety in general.

\section{General system theory in the description of road safety}

Since the 1960s of the 20th century, attention was drawn to usefulness of the systemic approach, introduced into the scientific circulation by von Bertalanffy [14]. Among other things, it was postulated that the road transport should be interpreted as a complex and open system, which allows to explain its inherent properties, hierarchical structure and interactive processes. Road accidents are the result of a failure to adapt the "structure" of this system to the cognitive abilities of road users. Eliminating some of the road accidents is possible by "matching" the traffic to road users. This can be achieved by systemically improving all the elements in the road traffic, i.e. by analyzing the effects of the whole. The lack of this methodology results, for example, in the "risk transfer" effect, which is the result of risk compensation by road users.

The basic argument for applying the systemic approach to transport safety issues is that the traditional, reductionist approach has serious limitations that can be forced through a holistic view of transport safety issues [15]. The reductionist approach does not primarily take into account the dynamic and blurred interactions between the transport participant, mode of transport and transport infrastructure [16].

The Skyttner's thesis that the system approach to road transport safety can play an important role: safety is emergent property of the road transport [17]. Thus, it is a system property that reveals itself when elements of the transport system cease to be independent and interact with each other. Emergency is the appearance of a new system property, as if from nowhere and unexpectedly. Of course not out of nowhere, but as a result of unobservable complex interactions on different levels of the system structure. Adopting the thesis about emergence means that it is the interactions between the elements of the transport system that are decisive in the occurrence of transport accidents - especially in road transport [18-19]. The issue of emergencies in general systems has a rich literature, see e.g. [20].

Levenson's observation is interesting in relation to "safety optimization" [19]. Well, the optimization of safety of particular elements or subsystems does not have to lead to the optimization of the whole system (for example, transport) due to complex and non-linear interactions between these elements.

If a systemic approach is adapted to the road safety testing, the complexity and dynamics of its processes can be explained by interactions between traffic participants, vehicles and road elements. Road safety, as well as other measures of "performance" of the traffic system, can be seen as properties resulting from incorrect interactions between the traffic system components. The systemic nature of the road safety problem is also referred to by $\mathrm{W}$. Haddon, who over 40 years ago gave an inspiring definition of road transport as: "an ill-designed "man-machine" system that requires comprehensive systemic treatment”; [13].

The emphasis on the need for a research approach based on "systems-oriented approach" appeared in OECD expert opinions [9, 21]. Systemic analysis is mentioned here as one of the disciplines belonging to the fourth paradigm of the road safety research, while the "system-oriented approach" should characterize the fifth research paradigm.

\section{Road transport as a complex system}

The transport system, which is analyzed over a large area and in the long term, can be interpreted as a complex system; it is justified here the definition of such systems [22]: A complex system is one of which development is very sensitive to initial conditions or small disruptions, where the number of independent interacting elements is large, or where there are many possible paths of development for the system.

Large transport systems have both known forms of complexity: 1 . chaotic complexity; 2 . organized complexity.

The first is the result of a very large number of elements (infrastructure elements, means of transport, human factor involved in implementation and participation in transport). The second one results from the course of transport working processes, mainly traffic processes. Safety depends on the strength of the functional links present in such systems. There are a tight and coupling connections. The former is characteristic of a decentralized and the latter of a centralized (hierarchical) management structure. This leads to a paradox that characterized C. Perrow: the system should be both centralized and decentralized. 
Large transport systems are complex systems, as they have the following features:

1. they have difficult to define boundaries; they are ultimately determined by the purpose and scope of the study;

2. they are open systems, according to the cybernetic approach;

3. they are memory-based systems; they are dynamic systems;

4. they are "embedded" systems, i.e. their subsystems are also complex systems in themselves;

5. they can "produce" emergencies (the emergence of new features);

6. the interactions between the elements of these systems are non-linear, which means that initially small transport incidents can have large effects;

7. there are feedback loops in the interactions between the elements, which means that there are both negative and positive (amplifying) feedback.

Transport systems also meet other criteria for complex systems:

8. they are intrinsically hazardous systems;

9. they contain mixtures of "hidden failures" (e.g incorrect design conditions);

10. the changes made generate new forms of damage (failures);

11. safety is a system characteristics, not an individual component.

In transport systems comes to huge numbers of interactions between elements of transport infrastructure, means of transport and the activities of the human factor. The products of these interactions are sometimes hard to predictable behaviors, systems, in particular, human behavior in the areas of decision-making and action. The ultimate product are transport accidents and congestion the main negative effects of transport /NET/ [23].

The work on road accident investigation methodologies often considers that the underlying causes of traffic accidents are mainly due to external (exogenous) rather than internal (endogenous) sources. This leads to the conclusion that the complexity of the road environment may in certain situations exceed the adaptability of road users, resulting in the generation of behavioral errors. From a sociotechnical point of view, 'complexity' of the system means that the road system is not properly designed for road users. This is confirmed: adapting the traffic system to the expectations of the road users is an important issue in the Swedish study "Vision Zero" (SVZ).

D. Woods identified complexity factors in those systems where the capabilities and skills of the human factor are important, i.e. in sociotechnical systems, which also include any transport system. In particular, he identified four "dimensions" with which he defined "cognitive requirements" to solve complexity problems in any field [24]:

1. Dynamism - the property of a system to generate events that cause changes;
2. Number of subsystems and the extent (extensiveness) of links between them;

3. Uncertainty - which refers to information about the investigated problem (phenomenon); this information may be ambiguous, imprecise, erroneous, incomplete;

4. Risk - which refers to the "nature" of different system results and their relative frequency.

These dimensions are also characterized by the complexity of transport systems, in particular traffic systems. The degree of system complexity depends on these dimensions. It is believed that the increase in complexity of any particular situation in the system under analysis increases the potential for cognitive and perception errors. Therefore, the greater the complexity of the situation, the greater the temporary instability of the system, which may increase the risk of accident. This thesis is consistent with results of general systems theory and can be fully applied in road safety research.

\section{Perrow's theory of "normal accidents". Transport accidents as system accidents}

Charles Perrow's main thesis of the "Normal Accident Theory" (NAT) reads [25]: Accidents in complex organizations ... are inevitable. This is exactly how road accidents must be understood globally: they are inevitable. Therefore, there remains only one rational strategy to improve the road safety - to eliminate fatal and serious accidents. Of course, this is known (SVZ), but 35 years ago the creator of NAT stated this, only in a general perspective.

What Perrow described as normal accidents or ordinary accidents, he also called, and later on others: systemic accidents or organizational accidents. According to Perrow, these are: unexpected interactions with many failures in a complex system. From more recent work on NAT, one can list [26-27].

The rather pessimistic Perrow's thesis about inevitable accidents in complex systems has its alternative; supporters of the "high reliability point of view" claim that good design and effective management in such systems can significantly reduce the probability of accidents [28-29].

It divides systems into simple and complex ones, depending on the type of interaction in these systems. Simple systems are those where simple interactions - i.e. predictable-such as those in the domino sets prevail. Systems are complex if complex interactions are predominant - i.e. unpredictable, coming from an accumulation of factors or aspects that, taken separately, appear to be without risk. The occurring complex interactions in the system are accompanied by an emergence that initiates unpredictable system behaviors that develop so quickly that the system operator no longer understands the resulting situation, making it irreversible and leading to a system accident. It is this aspect of safety that Perrow emphasizes when he says that "accidents in a complex system are inevitable". System accidents are the effects of an accumulation of the so-called 
"common-mode failure", which are created in the system by unknown feedback between system components.

An extensive definition of a systemic accident is given by Llory (1999); I quote de Almeida [30]: "The accident is organizational to the extent that it is, primarily, the product of a socio-technical organization. It is no longer only the result of an "unfortunate" combination of passive and latent failures with active and direct failures, no longer only the result of a specific combination of human errors and material failures". And on: The accident is "... rooted in the history of the organization: a series of decisions, or the absence of decisions; the evolution of the organizational, institutional and cultural context that interferes in the future of the system; the progressive evolution (deterioration) of conditions or factors that are inside the organization; some particular events that have a notable impact on the life and functioning of the socio-technical system, creating an unfavorable situation: territory into which the accident (or incident) may intrude and develop. [...] the accident incubates. The incubation period may be long..."

The frequency of occurrence of systemic accidents depends on many aspects of the functioning of a complex system, but most of all it depends on:

- the degree of "interactive complexity";

- the degree of "strong links" between system interactions.

The latter feature makes the system highly interdependent, i.e. changing one part of it can quickly affect the state of other parts and the whole system.

It would be interesting to verify the hypothesis on the frequency of system accidents in the road transport. It would need to be examined whether this frequency depends on the interactive complexity and strong links in large road transport systems, as well as in integrated transport systems. Possible "transport interpretations" of system accidents, known from other technical areas, would be of a great importance [19].

For a large road transport system to meet the criterion of "strong links" it would have to have the following characteristics [30]:

- most of the work processes are time dependent, i.e. the system cannot be stopped while waiting for corrective interactions to appear;

- $\quad$ specific and unchangeable sequences prevail, such that event A always leads to event B;

- the system is inflexible, i.e. planned in such a way that there is only one way to achieve the final goal.

Only the first criterion seems to be met by any road transport system. By contrast, the dangerous goods transport system would mostly meet these criteria.

\section{High reliability organizations (HRO) and transport safety management}

In 1984, a group of researchers from the University of California at Berkeley initiated research on complex systems, which was named High Reliability Organizations (HRO). The point is that there are systems whose integral parts are the highly dangerous technologies, and yet serious accidents hardly ever happen there. Those are systems in which errors and failures can have disastrous consequences for people and the environment. The matter of talking are the nuclear power, chemical industry, management systems in passenger aviation, maritime industry. So, the HROs are systems where disasters are avoided and where the so-called "normal accidents" are expected (a concept Perrow) due to the many risk factors and complexity of such systems.

How can one define the $H R O$ in the easiest way? According to K. Roberts, this can be done by answering the following question: how many times could such an organization fail without producing disastrous results? If the answer is: tens of thousands of times, it means that one is dealing with the $H R O$ [31]; quoted after: [32]. The key term "fail" here refers to the errors and malfunctions that may occur in such a system, and yet, there will be little consequence.

One may ask: are the large transport systems - which are, after all, complex systems - also the HRO type systems? So, can safety management in the road transport systems be implemented using the philosophy and methodology used in High Reliability Organizations? Large transport systems may sometimes be the $H R O$ systems' exemplifications; it is primarily about functioning of transport in the crisis management conditions, as well as the transport of hazardous materials. In general, however, road transport could not be classified as the $H R O$ systems, because [23]:

1) The potential consequences of individual road transport incidents are hardly ever catastrophic; of course, the extent of losses when dealing with road accidents over longer periods of time is catastrophic;

2) Road accidents are not rare events (in the probabilistic sense).

A review of the subject literature is contained in the paper [33].

\section{A new paradigm of systemic understanding of road safety}

Since 2000, when it was shown how a systemic approach to road safety management could be used, global, national and regional variants of this approach have begun to emerge. In the WHO report of 2004 [13] and the Auckland Regional Road Safety Plan 2009/12 - a characteristic of the "new" paradigm of understanding road safety can be found [34]:

1. Traffic injuries are highly predictable and can be prevented by a rational analysis of possible remedies.

2. Road safety is a multi-sectoral social health problem and it is impossible to achieve success in reducing road accidents without the full involvement of all actors (including other road risk "owners"). 


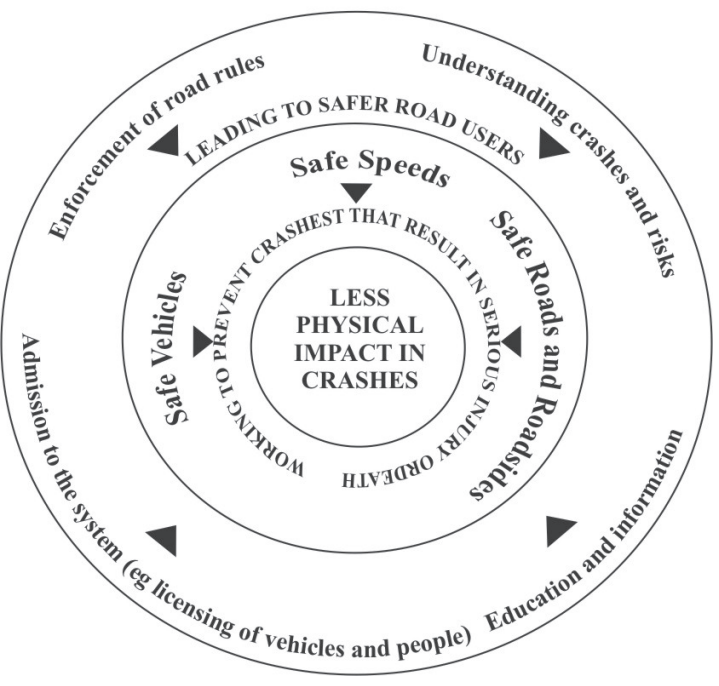

Figure 1 Systemic approach to road safety [35]

3. Any behavior of road users should not lead to death and serious injury; a traffic safety system should help all of them to cope with increasingly demanding conditions.

4. The sensitivity of the human body should be a control parameter (constraint) in the design for traffic and speed management systems.

5. Technology transfer should be in line with local conditions and the need to know how to implement local road safety solutions.

6. Injuries in road accidents can be interpreted as lost social capital and therefore all the road users should be equally protected, keeping in mind, however, that unprotected road users are subject to disproportionate risks and injuries in road accidents.

It is worth recalling here the definition of "human capital" [13]: this concept covers both direct costs and indirect costs for individuals and society as a result of road accidents; these costs include, among others: medical costs (initial, ad-hoc, rehabilitation), insurance costs, all the administrative costs related to the accident, occupational costs.

The ARRSP 2009/12 Regional Road Safety Programme contains an early version of the systemic approach to road safety management [34]. Hence, several conclusions, which are worth promoting:

1. There must be complementarity of roles and actions at all the levels of governance and social stakeholders in order to achieve the overarching objective of keeping the risk of the road accidents in the area to a minimum;

2. Road authorities, planners, investors must make efforts to plan, design and build sustainable and safe transport;

3. The necessary actions include

a) increasing safe access to all the modes of transport;

b) building "forgiving" transport infrastructure;

c) recognizing that vehicle speed management is at the heart of this approach.

This is the quintessence of the system approach expressed in a somewhat advertising form: "Safer road users using safe vehicles, travelling at safe speeds, on safe roads, will reduce the impact of sudden collision forces, which will cause less injury to people" [34].

A graphical interpretation of the systemic approach to road safety is shown in Figure 1.

Such a "road system" allows for human error, not leading to death or serious injury and responsibility for the risk reduction is shared between the road users and system managers.

\section{Road transport safety system (RTSS)}

The researcher's object of interest is "road transport", i.e. a certain real object in which one identifies entrances, exits, surroundings and various types of exchange that take place between the "transport-round" pair. Here, of course, it is possible to describe in detail such an object as the road transport considered in a certain area and at a certain time. It can be defined by describing the transport structure, means of transport and four main work processes:

1. initial and final processes (loading);

2. traffic processes;

3. traffic control processes;

4. disruptive processes - among other groups of transport system processes.

Different systems can be defined for such an object and each of them will describe specific properties of the analyzed object - that is the road transport. The property one is interested in is "safety" - therefore, the "road transport safety system" is defined, which must meet the following rigorous system method:

1. Accuracy: the system should be strictly defined so that it is clear what belongs and what does not belong;

2. Invariability: the definition of the system should be unchangeable; it is not acceptable that some elements of the system sometimes belong to the system and sometimes not to it;

3. Comprehensive: the division of the system into subsystems should be complete, which means that 


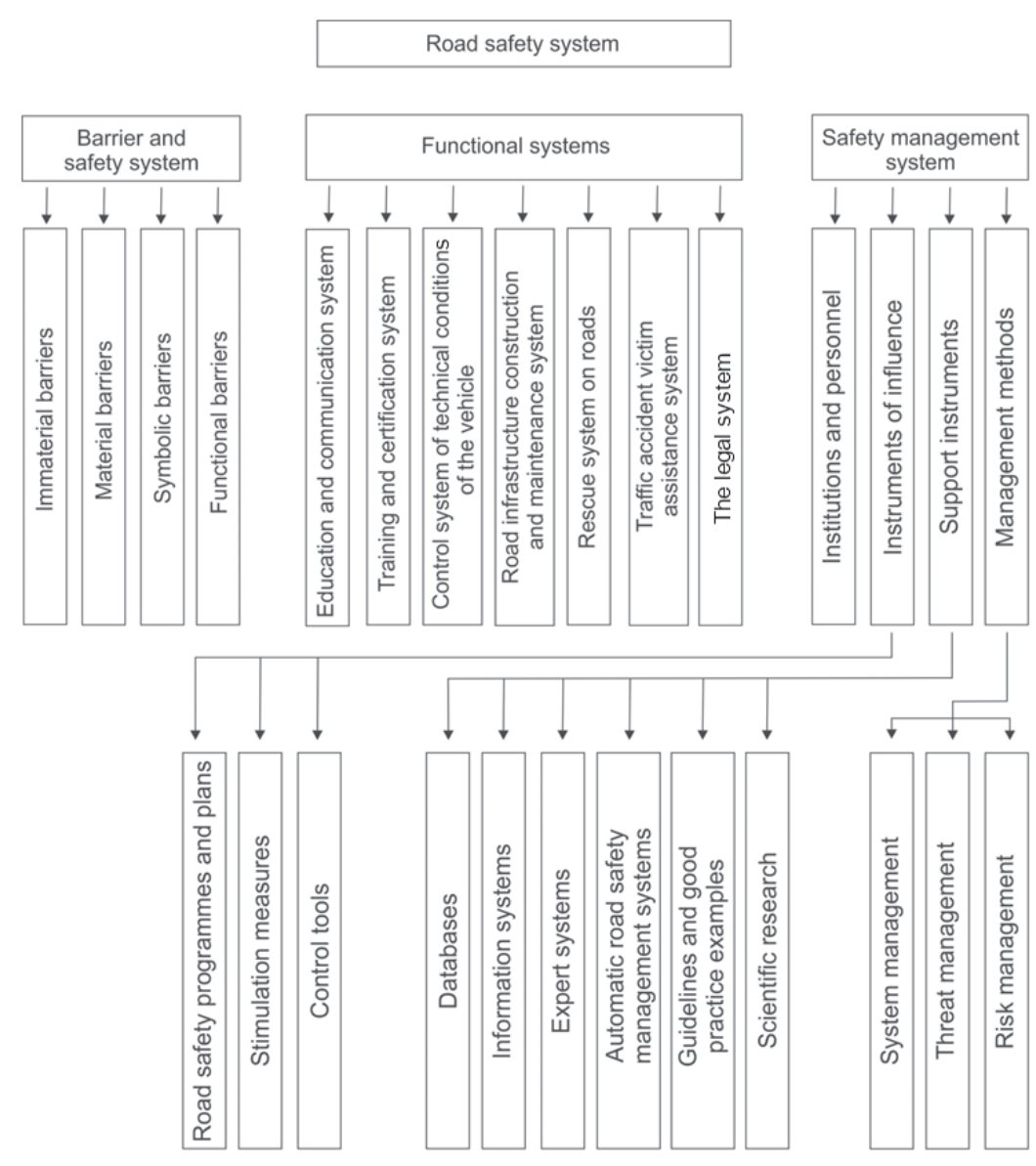

Figure 2 The road transport safety system [36]

the system must not contain elements, which do not belong to any of the subsystems;

4. Disconnection: the division of the system into subsystems should be separable. This means that a system must not contain elements belonging to several subsystems simultaneously;

5. Functionality: the system shall be kept separate according to the specific function performed.

The concept of the RTSS should be considered as a convenient conceptual abbreviation for everything that concerns the road transport safety, considered in a specific area and at a specific time. Thus, the RTSS is defined by the three components:

1) The purpose of the system - to reduce individual and social risks in different areas of transport operation;

2) A set of system components:

- The human factor in road transport;

- Technology (means of transport, road infrastructure, rescue and medical technology);

- Environmental factors;

- Four working processes: motion, control; initial and final, disruptive;

- Intangible components (standards, bans, procedures, etc.);

3) The system's relational structure, i.e. a set of relations (interactions) between elements of the system important for achieving the system's goal.
The RTSS defined in this way is a useful abstract and can be used to model various safety and road risk issues. Such a system can be described by the scheme shown in Figure 2.

\section{Conclusions}

Any road safety improvement programme requires the implementation of the 5E methodology (Education Engineering-Enforcement - Encouragement - Evaluation). These are components of the system approach. The construction of the road safety improvement programmes in Poland must be supported by scientific research - also those less known in Poland. This is research based on a systemic approach to road safety. In particular, several topics should be addressed:

1. Develop "transport interpretations" of system accidents known from the Perrow's theory of normal accidents [25].

2. Develop a Polish methodology for identifying gaps in the road traffic management system. It is primarily to identify the so-called hidden conditions of management failures and active management errors; the basis is the theory of J. Reason [37] and the works of Rassmussen, e.g. [38]. A little on this subject is also presented in the paper [39]. 
3. Develop methods for analyzing the road risk reduction potentials.

4. Continue work on the selection of criteria and methods of the risk analysis, which are the most useful for road transport systems [40].

5. Expand the road safety research (and more broadly transport safety) to risk studies in supply chains in which the road transport plays an important role [41]. Interesting are those studies that use the concept of Human Reliability Organizations (HRO) to describe and analyze supply chain disruptions [42].
Among the various systemic approaches to the road safety research in the article, the author's research results are briefly shown. They concern the following issues:

- Integrated risk management in the road safety system [36].

- $\quad$ Potential safety concept in modeling risk and supply chain reliability [41].

- Use of complex systems theory and the HRO concept in modeling the transport safety [23].

- Use of the „Swiss cheese model” and the LTSA model to identify "management gaps” in the Polish road transport system [39].

\section{References}

[1] PROSKE, D. Catalogue of risks. Berlin-Heidelberg: Springer-Verlag, 2008. ISBN 978-3-540-79555-1.

[2] MAIBACH, M., SCHREYER, C., SUTTER, D., VAN ESSEN, H. P., BOON, B. H., SMOKERS, R., SCHROTEN, A., DOLL, C., PAWLOWSKA, B., BAK, M. Handbook on estimation of external costs in the transport sector. Internalization measures and policies for all external cost of transport (IMPACT). Version 1.1. Delft, CE, 2008.

[3] Global Status Report on Road Safety 2018: summary. Geneva: World Health Organization, 2018. ILicence: CC BYNC-SA 3.0 IGO. ISBN 978-92-4-156568-4.

[4] CHEN, S, KUHN, M., PRETTNER, K., BLOOM, D. E. The global macroeconomic burden of road injuries: estimates and projections for 166 countries. The Lancet Planetary Health [online]. 2019, 3(9), p. e-390-e398 [accessed 202002-20]. ISSN 2542-5196. Available from: https://doi.org/10.1016/S2542-5196(19)30170-6

[5] EU Road Safety Policy Framework 2021-2030 - Next steps towards „Vision Zero” [online]. Commission Staff Working Document. SWD(2019) 283 final. Brussels: European Commission, 2019. Available from: https://ec.europa.eu/transport/ sites/transport/files/legislation/swd20190283-roadsafety-vision-zero.pdf

[6] Europe on the Move - sustainable mobility for Europe: safe, connected, and clean [online]. Communication from the Commission to the European Parliament, the Council, the European Economic and Social Committee and the Committee of the Regions. COM(2018) 293 final. Brussels: European Commission, 2018. Available from: https://eur-lex. europa.eu/resource.html?uri=cellar\%3A0e8b694e-59b5-11e8-ab41-01aa75ed71a1.0003.02/DOC_1\&format=PDF

[7] LU, M. Modelling the effects of road traffic safety measures. Accident Analysis and Prevention [online]. 2006, 38(3), p. 507-517. ISSN 0001-4575. Available from: https://doi.org/10.1016/j.aap.2005.11.008

[8] LU, M. Modelling and evaluation of the effects of traffic safety measures. Comparative analysis of driving assistance systems and road infrastructure. Doctoral thesis. Lund: Lunds Tekniska Hogskola, 2007. ISBN 978-91-628-7145-1.

[9] Road safety principles and models: review of descriptive, predictive, risk and accident consequence models. OCDE/ GD(97)153. Paris: OECD, 1997.

[10] LEVESON, N. G. Safeware: system safety and computers. New York: Addison-Wesley, 1995, p. $185-224$. ISBN 978-0201119725.

[11] SZYMANEK, A. Safety studies as a tied discipline / Nauka o bezpieczenstwie jako wiazana dyscyplina naukowa. In: Safety and Reliability International Conference KONBiN 2001 : proceedings [online]. Vol. 2. Warsaw: Wyd. ITWL, 2001. p. 337-350. Available from: https://doi.org/10.1126/science. 284.5411 .89

[12] GEYSEN, W. J. The structure of safety science: definitions, goals and instruments. In: 1st World Congress on Safety Science : proceedings. Vol. 1. 1990. p. 44-80.

[13] PEDEN, M., SCURFIELD, R., SLEET, D., MOHAN, D., HYDER, A. A., JARAWAN, E., MATHERS, C. World report on road traffic injury prevention. Geneva: World Health Organization, 2004. ISBN 92-4-156260-9.

[14] VON BERTALANFFY, L. General systems theory: foundations, development, applications. New York: George Braziller Inc., 1968. ISBN 978-0807604533.

[15] FILTNESS, A., THOMAS, P., TALBOT, R., QUIGLEY, C., PAPADIMITRIOU, E., YANNIS, G., THEOFILATOS, A., AIGNERBREUSS, E., KAISER, S., MACHATA, K., WEIJERMARS, W., VAN SCHAGEN, I., HERMITTE, T. The application of systems approach for road safety policy making [online] [accessed 2020-02-20]. Deliverable 8.1 of the H 2020 project Safety Cube. Loughborough: Loughborough University, Safety Cube, 2016. Available from: http://www.safetycubeproject.eu/safetycube-collaborates-with-partner-projects-april-2016/

[16] ZEIN, S. R., NAVIN, F. P. D. Improving traffic safety: a new system approach. Transportation Research Record: Journal of the Transportation Research Board [online]. 2003, 1830. ISSN 0361-1981, eISSN 2169-4052. Available from: https://doi.org/10.3141/1830-01 
[17] SKYTTNER, L. General systems theory. Problems - perspective - practice. Singapore: World Scientific Publishing Co. Pte. Ltd., 2005. ISBN 978-9812564672.

[18] HOLLNAGEL, E. Barriers and accident prevention. Hampshire, England: Ashgate Publishing Ltd., 2004. ISBN 978-1138247352.

[19] LEVESON, N. G. A New approach to system safety engineering [online] [accessed 2020-02-20]. Massachusetts: Aeronautics and Astronautics, Massachusetts Institute of Technology, 2002. Available from: http://ocw.mit.edu

[20] PARIES, J. Complexity, emergence, resilience. In: Resilience engineering - concepts and precepts. HOLLNAGEL, E., WOODS, D. D., LEVESON, N. (eds.). Aldershot, England: Ashgate Publishing Limited, 2006. ISBN 978-0754649045.

[21] Road safety: what's the vision? - Organization for Economic Cooperation and Development: OECD [online] [accessed 2020-02-20]. OECD, Paris, 2002. Available from: http://www.internationaltransportforum.org

[22] WHITESIDES, G. M., ISMAGILOV, R. F. Complexity in chemistry. Science. 1999, 284(5411), p. 89-92. ISSN 1095-9203.

[23] SZYMANEK, A. Theory of complex systems and the high reliability organization concept in transport safety modeling. In: 22nd International Scientific Conference Transport Means 2018 : proceedings. Part II. 2018. ISSN 1822-296X, eISSN 2351-7034, p. 828-833.

[24] WOODS, D. Coping it complexity: the psychology of human behavior in complex systems. In: Tasks, errors, and mental models. GOODSTEIN, L. P., ANDERSEN, H. B., OLSEN, E. E. (eds.). London: Taylor and Francis, 1986, p. 128-148. ISBN 978-0-85066-401-0.

[25] PERROW, C. Normal accidents: living with high risk technologies. New York: Basic Books, 1986. ISBN 978-0691004129.

[26] LE COZE, J.-CH. 1984-2014. Normal accidents. Was Charles Perrow right for the wrong reasons? Journal of Contingencies and Crisis Management [online]. 2015, 23(4), p. 275-286 [accessed 2020-02-20]. eISSN 1468-5973. Available from: https://doi.org/10.1111/1468-5973.12090

[27] TURNER, N., GRAY, G. C., SHRIVASTAVA, S., SONPAR, K., PAZZAGLIA, F. Normal accident theory versus high reliability theory: a resolution and call for an open systems view of accidents. Human Relations [online]. 2009, 62(9), p.1357-1390 [accessed 2020-02-20]. ISSN 0018-7267. Available from: https://doi.org/10.1177/0018726709339117

[28] HOPKINS, A. The problem of defining high reliability organizations [online] [accessed 2020-02-20]. Working Paper 51. Canberra: National Research Centre for OHS Regulation, Australian National University, 2007. Available from: http://citeseerx.ist.psu.edu/viewdoc

[29] ENYA, A., PILlAY, M., DEMPSEY, S. A Systematic review on high reliability organisational theory as a safety management strategy in construction. Safety [online]. 2018, 4(1), 6. eISSN 2313-576X. Available from: https://doi.org/10.3390/safety4010006

[30] ALMEIDA, I. M. Systemic approach to accidents and occupational health and safety management. Interfaces A Journal on Integrated Management of Occupational Health and the Environment [online]. 2006, 1(2), Art 1 [accessed 2020-02-20]. ISSN 1980-0908. Available from: http://www3.sp.senac.br/hotsites/blogs/InterfacEHS/wp-content/uploads/ 2013/07/2006-v2-art1-ingles.pdf

[31] ROBERTS, K. H. Some characteristics of high-reliability organizations. Organization Science [online]. 1990, 1(2), p. 160. ISSN 1047-7039, eISSN1526-5455. Available from: https://doi.org/10.1287/orsc.1.2.160

[32] MARAIS, K., DULAC, N., LEVESON, N. Beyond normal accidents and high reliability organizations: The need for an alternative approach to safety in complex systems. In: Engineering Systems Division Symposium : proceedings [online] [accessed 2020-02-20]. 2004. Available from: http://sunnyday.mit.edu/papers/hro.pdf

[33] LEKKA, CH. High reliability organisations - a review of the literature [online]. RR899 Research Report. London: Health and Safety Executive, 2011. Available from: https://www.hse.gov.uk/research/rrpdf/rr899.pdf

[34] Auckland regional road safety plan 2009/12. Creating a safer transport system for Aucklanders [online] [accessed 202002-20]. The Auckland Regional Transport Authority (ARTA), 2009. Available from:http://www.roadsafeauckland.org. $\mathrm{nz}$

[35] NEWTON, J. Road safety - partnership program. Shared responsibility [online] [accessed 2020-02-20]. Western Australia: Office of Road Safety, 2008. Available from: http://www.officeofroadsafety.wa.gov.au

[36] JAMROZ, K., SZYMANEK, A. Integrated risk management in the road traffic safety system / Zintegrowane zarzadzanie ryzykiem w systemie bezpieczenstwa ruchu drogowego (in Polish). Transport Miejski i Regionalny / Urban and Regional Transport. 2020, 4, p. 30-36. ISSN 1732-5153.

[37] REASON, J. Human error [online]. Cambridge: Cambridge University Press, 1990. eISBN 9781139062367. Available from: https://doi.org/10.1017/CBO9781139062367

[38] RASMUSSEN, J. Safety research and the technological development. In: 1st World Congress on Safety Science : proceedings. Vol. 1. 1990. p. 364 - 377.

[39] SZYMANEK, A. The concept of using SCh-M and LTSA models to identify management gaps in the Polish road safety system. In: 23rd International Scientific Conference. Transport Means 2019 : proceedings. Sustainability: Part III. Research and Solution. ISSN 1822-296X, eISSN 2351-7034, p. 1170-1174. 
[40] ARCHER, J. Indicators for traffic safety assessment and prediction and their application in micro-simulation modelling: a study of urban and suburban intersections. Doctoral dissertation. Stockholm: Royal Institute of Technology, 2005. ISSN 1651-0216, ISBN 91-7323-1193.

[41] SZYMANEK, A. Potential concept of security in risk modeling and supply chain reliability / Potencjalowa koncepcja bezpieczenstwa w modelowaniu ryzyka i niezawodnosci łancucha dostaw (in Polish). Logistyka. 2010, 2, p. 121-125. ISSN 1231-5478.

[42] MARLEY, K. A. Mitigating supply chain disruptions: essays on lean management, interactive compexity and tight coupling. Doctoral dissertation. Ohio: Graduate School of The Ohio State University, 2006. 